\title{
METHODOLOGY
}

\section{Immunofluorescence in cytogenetic analysis: method and applications*}

\author{
Peter Jeppesen \\ MRC Human Genetics Unit, Western General Hospital, Edinburgh, EH4 2XU, Scotland, UK. E-mail: peter.jeppesen@hgu.mrc.ac.uk \\ *Presented at the International Graduate School Course and Workshop on "New Approaches in the Study of \\ Radiation-Induced and Cancer-Associated Chromosomal Aberrations"
}

\begin{abstract}
Control of the genetic information encoded by DNA in mammalian chromosomes is mediated by proteins, some of which are only transiently attached, although others are intrinsically associated with nucleic acid in the complex mixture known as chromatin. Chromatin-associated proteins range from the ubiquitous and abundant histones down to the most specific and rare of transcription factors. Although many chromatin proteins are probably excluded from highly condensed mitotic chromosomes, a number are retained throughout the cell cycle and can be detected on chromosomes in metaphase spreads. Comparing the distribution of a chromosomal protein with known cytogenetic markers on metaphase chromosomes can provide an important and potentially highly informative first source of data on the function of the protein under consideration. The aim of the present study is to summarize some of the principles involved in obtaining suitable chromosome preparations for subsequent immunolocalization of protein antigens. Some applications of the method will be included to illustrate how this approach has increased our understanding of chromosome structure and genetic regulation.
\end{abstract}

\section{INTRODUCTION AND BACKGROUND}

Many antigenic determinants are adversely affected by the methods traditionally employed for the preservation or fixing of biological specimens. Thus, fixation is aimed at rendering cellular constituents immutable and/or insoluble, which is usually achieved by denaturation or chemical cross-linking of proteins and other macromolecules. However, antigenicity is often drastically reduced by these same procedures. For immunological study of chromosomes the difficulty is compounded by the fact that the method of choice for obtaining good metaphase chromosome spreads, namely acid fixation, also extracts histones and other basic chromatin-associated proteins, and hence generally destroys chromatin structure. Whereas this is not a problem, and may be a positive advantage, for cytogenetic analysis by techniques such as chromosome band- ing and fluorescence in situ hybridization (FISH), it is clearly a barrier to understanding the in vivo organization of chromosomal components. The methods that will be described here were developed to retain as near a native chromosome structure as possible during the immunolabelling process, while still allowing individual chromosomes to be identified subsequently by more traditional cytogenetic methods.

Cytocentrifugation has been used as an alternative to acid-fixation for immunofluorescence labelling of metaphase chromosomes and nuclear antigens. Stenman et al. (1975) described a procedure involving a low ionic strength salt solution for hypotonically swelling cells and medium for centrifuging the swollen cells onto microscope slides, which were then fixed in ethanol:acetone $(1: 1)$ prior to antibody reactions. In an attempt to avoid fixation altogether, the method to be described here made use of a technique that had previously been developed in this laboratory for the preparation of isolated metaphase chromosome suspensions (Gooderham and Jeppesen, 1983). It had been shown that metaphase chromosomes were stable in an isotonic medium based on potassium chloride and containing Triton X-100 (potassium chromosome medium, KCM). $\mathrm{KCM}$ could contain low concentrations of divalent cations for extra compact chromosome morphology, or EDTA for a looser structure that still retained a native appearance when viewed by phase-contrast light microscopy. The cytocentrifugation procedure was therefore modified to use a hypotonic $\mathrm{KCl}$ solution for cell swelling and centrifugation onto glass slides, followed by transfer to KCM (EDTA) for pre-equilibration before incubating with antibodies. The Triton X-100 solubilized cellular membranes and liberated cytosol, but chromosomes and nuclei were retained adhering to the glass support, and could be gently handled during subsequent immunolabelling (also carried out in $\mathrm{KCM}$ ) without any further fixation. This procedure seemed to provide the least perturbation of native chromosome organization in which to analyze the distribution of nuclear antigens. 


\section{MATERIAL AND METHODS}

Cytocentrifugation of unfixed cell preparations on microscope slides and subsequent localization of nuclear antigens by indirect immunofluorescence are carried out by methods developed in this laboratory that have essentially been described elsewhere (Jeppesen et al., 1992; Jeppesen and Turner, 1993; Jeppesen, 1993). A few minor modifications to the original procedures have been introduced over time, and for the examples used to illustrate this article that cite previously published material, the precise experimental details used in each case can be found by reference to the original work. What follows is a general protocol that we currently use for immunolocalization of a number of different nuclear and chromosomal antigens in a wide range of cell types, together with some comments on the rationale behind certain key steps in the procedure. Antibodies and cell types used in the examples are listed below.

\section{Antibodies}

R5/12 anti-acetylated histone $\mathrm{H} 4$ rabbit antiserum specifically recognizes $\mathrm{H} 4$ acetylated at lysine- 12 and preferentially binds to the more highly acetylated isoforms (Turner and Fellows, 1989). Sheep antiserum S613, which also binds preferentially to hyperacetylated histone $\mathrm{H} 4$, was developed in collaboration with the Scottish Antibody Production Unit (SAPU), Carluke, Scotland, and was affinity purified before use (unpublished results). Rabbit anti$\mathrm{MeCP} 2$ antiserum was obtained from Upstate Biotechnology, USA. Sheep anti-human MBD1 antiserum was prepared as described (Ng et al., 2000).

\section{Cells and cell lines}

Human lymphocytes were separated from blood samples, stimulated with PHA and cultured for $72 \mathrm{~h}$ as described previously (Jeppesen et al., 1992). HF19 is a primary human female cell line (Jeppesen and Turner, 1993). $\mathrm{AL}$ is also a primary human female cell line but derived from a subject possessing a ring $\mathrm{X}$ chromosome (Migeon et al., 1994). C127 is a fibroblast-like mouse mammary tumour cell line (ATCC CRL 1616). Transgenic mouse cell lines were established by SV40 transformation of chimeric embryo fibroblast cultures (Migeon et al., 1999).

\section{Preparation of metaphase cell spreads by cytocentrifugation}

Metaphase arrest is induced in stimulated lymphocytes and lymphoblastoid cell lines in suspension culture by adding colcemid at a final concentration of $0.1 \mu \mathrm{g} / \mathrm{ml}$ to dividing cells for $1-2 \mathrm{~h}$. The cells are then collected by centrifugation at $1000 \mathrm{rpm}$.

Cells in monolayer culture are grown to confluency in an appropriate medium, and then sub-passaged at a split ratio of 1:5. This leads to a semi-synchronous burst of cell division approximately $24 \mathrm{~h}$ later for most cell types. Cells are then arrested in metaphase by the addition of $0.1 \mu \mathrm{g} / \mathrm{ml}$ colcemid for $1-2 \mathrm{~h}$. The supernatant medium is then removed and kept on ice while the cells are detached from the surface of the culture vessel by incubation with Trypsin-EDTA (TE): $0.05 \%$ (w/v) trypsin (1:250), 0.02\% EDTA in buffered saline (3-4 ml TE/10 ml culture medium). The detached cell suspension in TE is then removed to a centrifugation tube, the culture vessel washed with an equal volume of the stored supernatant medium which is mixed with the TE suspension, and the cells are collected by centrifugation at $1000 \mathrm{rpm}(5 \mathrm{~min})$. The cell pellet is then resuspended in the remaining stored supernatant culture medium and the cells finally collected by centrifuging once more at $1000 \mathrm{rpm}$. This procedure fulfils two main functions: 1) rounded-up metaphase cells that may become detached from the surface when removing the supernatant culture medium are not lost; 2) all residual trypsin activity is abolished by trypsin inhibitors present in the serum contained in the culture medium. A technique frequently employed for enriching metaphase cells from monolayer culture by 'shaking off' the loosely attached mitotic cells is not recommended for the cytospin method described here. As will be explained, cells need to be cytocentrifuged at a minimum density to obtain efficient spreading, and it is more convenient to achieve the required density by including a majority of interphase cells in the preparations.

Cells from both suspension and monolayer cultures are then treated identically as follows. All but approximately $0.2-0.3 \mathrm{ml}$ of supernatant medium is discarded from the $1000 \mathrm{rpm}$ cell pellets, which are then resuspended in the residual medium by gentle agitation and cooled on ice. One $\mathrm{ml}$ of $75 \mathrm{mM} \mathrm{KCl}$ hypotonic at $4^{\circ} \mathrm{C}$ is then added dropwise to the cell suspension with continuous gentle agitation. Keeping the suspension cool, it is then drawn up and down a pipette tip a few times to ensure complete homogenization, after which 2-3 $\mathrm{ml}$ further hypotonic is added and gently mixed in. Cells are allowed to swell at $37^{\circ} \mathrm{C}$ for $15 \mathrm{~min}$, after which they are transferred to ice again, with occasional gentle agitation to keep in suspension, while the cell density is determined by counting using a hemocytometer or other cell counting device.

Cells are then cytocentrifuged by the 'dry' technique: excess cell suspension medium is removed during centrifugation by an absorbant filter card placed between the glass slide and the sample chamber. Different manufacturers of cytocentrifuges have slightly different systems, but the general principles are the same: the author uses the Ames Cytotek, manufactured by Sakura, Japan. It is important that cells are cytocentrifuged at roughly the correct density: the ideal is just below a monolayer, so that there is some space between cells. In the author's experience, too sparse a density not only leads to fewer metaphases in the sample 
area, but also to poorer morphology of nuclei and chromosomes (Jeppesen et al., 1992). The latter effect is, however, to a certain extent alleviated by the inclusion of Tween 20 (see below). The correct density for a given cytocentrifuge must be determined for each cell type by trial. The hypotonically swollen cell suspension is diluted appropriately in $75 \mathrm{mM} \mathrm{KCl}$ containing $0.1 \%$ Tween 20 for centrifugation on clean glass microscope slides.

The inclusion of Tween 20 in the cytocentrifugation medium is a relatively recent innovation, and derives from problems experienced previously with lymphocytes and lymphoblastoid lines. These cell types tended to aggregate in large clumps during cytocentrifugation in $75 \mathrm{mM}$ $\mathrm{KCl}$ alone, making it difficult to obtain individual, wellspread metaphases. The addition of the mild surface active agent Tween 20 was found to give a much more even distribution of cells over the slide surface, without causing dissolution of the cell membrane. Fortuitously, Tween 20 also appears to reduce the number of cells spontaneously disrupting during cytocentrifugation, even at low cell densities (Jeppesen et al., 1992), and also seems to increase the efficiency of cell adhesion to the glass surface. The overall improvement in chromosome and nuclear morphology effected by Tween 20 has resulted in its routine inclusion during cytocentrifugation for all cell types. Using the Cytotek centrifuge, it has been found that $0.5 \mathrm{ml}$ of cell suspension at a final density of $0.5 \times 10^{5}$ cells $/ \mathrm{ml}$ in 75 $\mathrm{mM} \mathrm{KCl}+0.1 \%$ Tween 20 is about the right quantity of many types of cell for centrifugation into the $6 \mathrm{~mm} \times 6$ $\mathrm{mm}$-square sample area. Especially large or small cells may require slight adjustment down and up, respectively, of the cell density.

After cytocentrifugation, slides are allowed to dry for a few minutes before being transferred to a Coplin jar containing KCM $(120 \mathrm{mM} \mathrm{KCl}, 20 \mathrm{mM} \mathrm{NaCl}, 10 \mathrm{mM}$ Tris$\mathrm{HCl}, \mathrm{pH} 7.5,0.5 \mathrm{mM}$ EDTA, $0.1 \%$ (v/v) Triton X-100) for 10-15 min at room temperature. During KCM treatment, the cell membrane is solubilized and many cytoplasmic components are washed out, leaving behind nuclei and metaphase chromosomes adhering to the glass slide surface, on which they may be handled gently for subsequent antibody incubations without fixation, provided the sample area remains bathed in $\mathrm{KCM}$. The $\mathrm{pH}$ for $\mathrm{KCM}$ has been reduced slightly from the $\mathrm{pH} 8.0$ used previously (Jeppesen et al., 1992) to avoid possible adverse effects on chromosome morphology of exposure to mildly alkaline conditions should the $\mathrm{pH}$ drift slightly upwards.

Although antibody incubations are usually performed immediately after cytocentrifugation and KCM pre-treatment, if experimental schedules are such that this is not possible, slides may be stored dry at $4^{\circ} \mathrm{C}$ after cytocentrifugation (for example, overnight) before transfer to $\mathrm{KCM}$. Antibody reactions do not appear to be affected unduly by this procedure, but cellular proteins seem to undergo partial fixation by prolonged storage, resulting in more cytoplasmic components being retained and possi- bly a higher background of non-specific antibody binding. In this situation, an increase in KCM pre-treatment of up to $1 \mathrm{~h}$ may help.

\section{Antibody incubation and immunofluorescence}

Cytocentrifuged metaphase chromosomes and nuclei on microscope slides are relatively stable without fixing if maintained in KCM. Therefore, antibody incubations are carried out in KCM, which acts as a good immunoreaction medium. Primary antibody binding is detected by a subsequent incubation with fluorescently conjugated secondary antibody (indirect immunofluorescence). Both primary and secondary antibodies are diluted in $\mathrm{KCM}$ containing $10 \%(\mathrm{v} / \mathrm{v})$ normal serum from a noncrossreacting species, preferably the one in which the secondary antibody was raised. Non-specific antibodybinding sites in the specimens are effectively blocked by the excess normal serum, leading to low levels of background fluorescence. Primary whole antisera are diluted in the range $1: 100$ to $1: 500$, depending on antibody titer. Purified and monoclonal antibodies may need less dilution. Secondary antibodies are diluted according to the manufacturer instructions, usually between 1:10 and 1:20.

Slides are removed from the KCM pre-treatment and the glass around the cell area is carefully blotted dry with a tissue, after which approximately $40 \mu 1$ of diluted antibody is applied to the specimen. A $15-\mathrm{mm}$ square of parafilm is used to cover and contain the antibody solution to the specimen area, in preference to a glass coverslip, as it is easier to remove, and evaporation is reduced by transferring the slide to a humid chamber at room temperature. After 1-2$\mathrm{h}$ primary antibody incubation, the parafilm is lifted off with forceps and the antibody solution gently rinsed off with approximately $1 \mathrm{ml}$ of KCM gently directed from a pipette. The slide is washed twice more by immersion for 5 min each time in KCM contained in Coplin jars, after which the secondary antibody incubation is carried out in a similar manner to the primary incubation, for $30 \mathrm{~min}$. Following rinsing and $2 \times 5$-min washes in $\mathrm{KCM}$ as before, the slides are finally fixed in KCM containing 4\% $(\mathrm{w} / \mathrm{v})$ formaldehyde for $15 \mathrm{~min}$, washed for $5 \mathrm{~min}$ in distilled water, and allowed to dry in air. Slides are counterstained for $10 \mathrm{~min}$ with $0.5 \mu \mathrm{g} / \mathrm{ml}$ Hoechst 33258 , or another suitable DNA fluorochrome such as DAPI or propidium iodide, and mounted for fluorescence microscopy in anti-fade mountant.

\section{EXAMPLES AND DISCUSSION}

\section{Histone $\mathrm{H} 4$ acetylation}

One of the first significant results to be obtained with the development of the cytospin method described here was the analysis of histone $\mathrm{H} 4$ acetylation on mammalian metaphase chromosomes (Jeppesen et al., 1992; Jeppesen 
and Turner, 1993). It had been recognized that the modification of histones by acetylation was correlated by a number of criteria with gene expression and transcription. It might have been expected, therefore, that transcriptionally inactive mitotic chromosomes would be lacking in histone acetylation. Howewer, when murine metaphase chromosomes were probed with an antibody that specifically recognized hyperacetylated histone H4 (Figure 1A,B), it was evident that a pattern of $\mathrm{H} 4$ acetylation was retained that seemed to reflect the transcriptional activity of the corresponding chromosomal domains during interphase. Especially noticeable were the underacetylation of constitutive pericentric heterochromatin and the facultatively heterochromatinized inactive X chromosome in female cells, and the non-uniform labelling of euchromatin, giving a banded appearance to the chromosome arms. When this result was repeated in human cells (Figure 1C,D) and the euchromatin banding analyzed in detail (Figure 1E), it was found that it corresponded very closely with the conventional R-banding pattern that other investigations had shown was in turn correlated with GC content and gene distribution in the genome (Holmquist, 1992). Indeed, the most highly acetylated bands corresponded to the location of T-bands, the most GC-rich subset of R-bands where the highest gene density, and hence the highest transcriptional activity during interphase, was found. Cytogenetic analysis of histone $\mathrm{H} 4$ acetylation, therefore, had not only verified that acetylation was linked in a very localized and specific way with
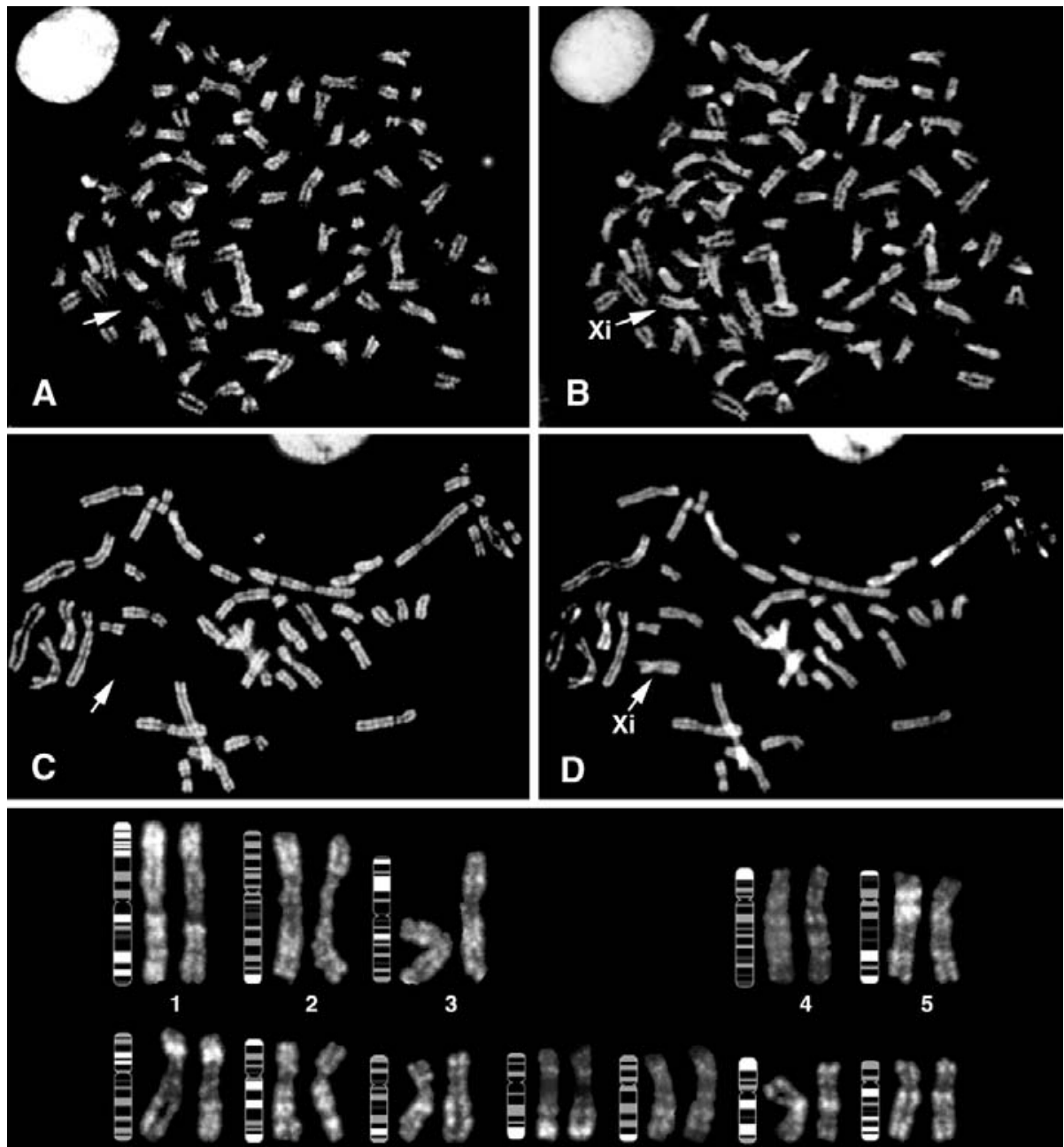

9
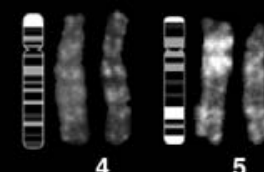

6

7

8

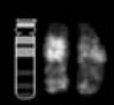

13
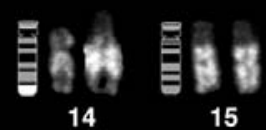

14

15

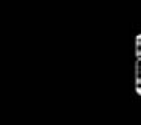

10

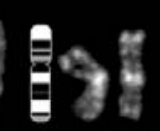

11

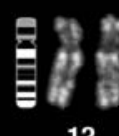

12
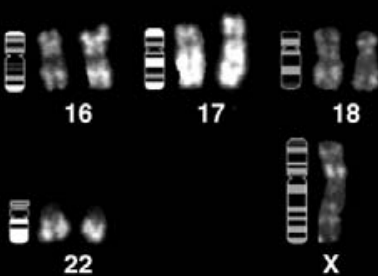

Figure 1 - Distribution of histone $\mathrm{H} 4$ hyperacetylation on mammalian metaphase chromosomes. A,B - Mouse mammary tumour line C127 metaphase cell: A) indirect immunofluorescent labelling with affinity-purified sheep S613 anti-acetylated histone $\mathrm{H} 4$ antibody, diluted 1:20, detected with FITCconjugated donkey anti-sheep $\mathrm{IgG}$; B) Hoechst 33258 fluorescent image of the same cell. The arrow in A points to the position of the underacetylated inactive $\mathrm{X}$ chromosome (Xi), which can be seen in B. C,D Primary human female fibroblast line HF19 metaphase cell: C) indirect immunofluorescent labelling of chromosomes with R5/12 anti-acetylated histone $\mathrm{H} 4$ rabbit antiserum, detected with FITC-goat anti-rabbit IgG (Jeppesen and Turner, 1993); D) ethidium bromide fluorescent image of the same cell. The arrow in $\mathbf{C}$ points to the position of the $\mathrm{Xi}$, seen in D. E - Histone H4 acetylation karyotype of human metaphase chromosomes (female). The standard R-band ideograms, to the left of each autosome-pair and the single labelled $X$ chromosome, show the close correspondence between R-bands and H4 acetylation (Jeppesen, 1997). 
transcriptionally active chromatin domains, but also that this link was maintained through the transcriptionally inactive mitotic phase of the cell cycle. A possible explanation of this indirect connection with transcription is that histone acetylation may provide the basis for a mechanism of epigenetic regulation of gene expression through chromatin modification (Jeppesen, 1997).

\section{$\mathrm{X}$-inactivation}

The ability to recognize $\mathrm{X}$-inactivated chromatin by its lack of histone $\mathrm{H} 4$ acetylation has led to a number of interesting applications. One such was a study of X chromosome loss in ageing females. It has long been recognized that, compared with autosomes, $\mathrm{X}$ chromosomes are preferentially lost in the female population, and that the loss increases with age. One possible explanation is that inactive $\mathrm{X}$ chromosomes, by virtue of their facultatively heterochromatinized state, are more prone to loss during cell division than autosomes. To test this hypothesis, an experiment was devised to look at chromosome loss immediately after mitosis, before selection to eliminate cells missing active chromosomes could occur. Lymphocytes from differently aged female volunteers were stimulated to divide with phytohemagglutinin. For the final $28 \mathrm{~h}$ of culture, cytochalasin $\mathrm{B}$ was added to the medium to inhibit cytokinesis, after which cytospin cell preparations were made and immunolabelled with anti-acetylated histone $\mathrm{H} 4$ antibodies as described above. When the slides were analyzed, binucleate cells that had just undergone mitosis but not cell division were evident, and a small fraction of these possessed, in addition, a micronucleus containing a chromosome or fragment that had been excluded from both daughter nuclei (Figure 2). Under normal cell division, such micronuclei would lead to clonal populations of cells lacking the mis-segregated chromosome. To identify micronuclei containing $\mathrm{X}$ chromosomes, the immunolabelled slides were subjected to simultaneous FISH with an X-alphoid DNA probe. The FISH data showed that X chromosomes were indeed over-represented in micronuclei, compared to the autosomes, and that the number increased with the age of the donor. However, half of the X chromosome-containing micronuclei were normally acetylated compared to the nuclei, and half were underacetylated. Thus, both active and inactive $\mathrm{X}$ chromosomes are equally likely to be lost during cell division, and their increased likelihood compared to autosomes must be intrinsic to the $\mathrm{X}$ chromosome itself, rather than attributable to X-inactivation (Surrallés et al., 1996). An important corollary of this result was the first direct observation of $\mathrm{H} 4$ underacetylation on inactive $\mathrm{X}$ chromosomes during interphase (i.e., in micronuclei), confirming the data from metaphase chromosomes.

Another application that has particular relevance for a meeting primarily concerned with chromosomal aberrations and abnormalities, was the analysis of the activity status of ring $\mathrm{X}$ chromosomes in female patients possessing mosaic ring $\mathrm{X}$ karyotypes. In females with two potentially functional $\mathrm{X}$ chromosomes, one is normally randomly selected for inactivation, to preserve $\mathrm{X}$-linked gene dosage equality between males and females. Ring X chromosomes arise from large terminal deletions in both arms of one $\mathrm{X}$ chromosome through chromosome breakage, followed by resealing of the broken ends, retaining the centromere. In most cases, the effect is mild and similar to Turner's syndrome, since only cells in which the ring X chromosome undergoes X-inactivation survive. Occasionally, however, the effects of possessing a ring $\mathrm{X}$ chromosome were found to be much more severe, with the affected patient subject to congenital malformations and mental retardation. To explain these cases, it was suggested that in these individuals the ring $\mathrm{X}$ chromosome was deleted for all or part of the $\mathrm{X}$ inactivation center (XIC), and therefore failed to undergo $\mathrm{X}$-inactivation. Thus, in cells containing an active ring $\mathrm{X}$ chromosome, the products of genes retained on the ring were potentially present in double quantity, which resulted in the observed abnormalities. The rings in which this was proposed to occur were extremely small, and their activity status could not be determined by conventional cytogenetic procedures, i.e., BrdU incorporation or Kanda banding. By the use of immunofluorescent labelling with anti-acetylated histone $\mathrm{H} 4$ antibodies, however, it was possible to distinguish active from inactive ring $\mathrm{X}$ chromo-

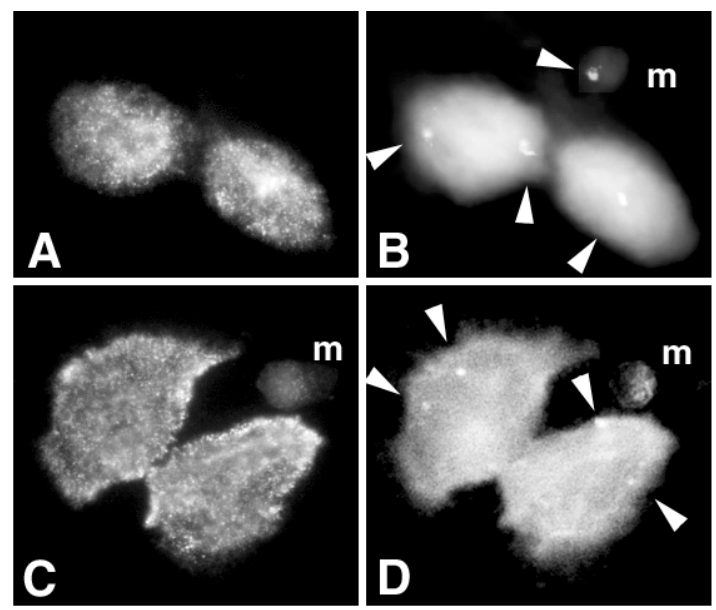

Figure 2 - Histone H4 acetylation on interphase chromosomes. A,B - Binucleate human female lymphocyte with micronucleus (m) containing inactive $\mathrm{X}$ chromosome, following cytochalasin-B treatment to inhibit cytokinesis: A) underacetylation of micronucleus shown by lack of immunofluorescence with $\mathrm{R} 5 / 12$ anti-acetylated histone $\mathrm{H} 4$ rabbit antiserum detected with FITC-goat anti-rabbit IgG (Surrallés et al., 1996); B) DAPI fluorescent image of the same cell, with positions of interphase X chromosomes identified by superimposed rhodamine X-alphoid probe FISH image (arrowheads), showing labelling of micronucleus. The lack of $\mathrm{H} 4$ acetylation (A) indicates that the micronucleus contains a mis-segregated inactive X chromosome. C,D - Comparison with micronucleus (m) showing a normal level of $\mathrm{H} 4$ acetylation: $\mathbf{C}$ ) binucleate cell prepared and labelled with R5/12 antiserum as in A; D) DAPI fluorescent image of the same cell including X-alphoid FISH, as in B. The four FISH signals (arrowheads) within the nuclei show that the micronucleus harbours an autosome. 
somes (Figure 3A-D), and the hypothesis that a failure to inactivate ring $\mathrm{X}$ chromosomes led to patients with the severe phenotype was verified. Further analysis of ring $X$ chromosomes from subjects with mild and severe phenotypes demonstrated a requirement not only for XIST, a candidate gene for the XIC, but also for XIST transcription, to enable cis inactivation to occur (Migeon et al., 1994).

More recently, a yeast artificial chromosome (YAC) containing the minimum XIC was used to transfect male mouse embryonic stem (ES) cells, leading to stable integration of the human XIC region into mouse autosomes. A cloned transfectant line ES-10 contained approximately six tandemly repeated copies of XIST inserted near the telomere of the long arm of mouse chromosome 11. When ES10 cells were injected into mouse blastocysts, giving rise to chimeric embryos, RNA transcription studies showed that human XIST was expressed in a number of tissues. In fibroblast lines derived by SV40 transformation of chimeric embryo cultures, however, although there was evidence of localized gene silencing close to the transgene on chromosome 11, immunofluorescence analysis with anti-acetylated histone $\mathrm{H} 4$ antibody (Figure 3E) failed to detect spreading of underacetylation, and hence inactivation, away from the site of integration (Migeon et al., 1999). In contrast to inactivation occurring in an X chromosome, it seems that there is some barrier to gene silencing spreading along an entire autosome. Significantly, however, in $4 \%$ of tetraploid fibroblasts containing the transgene, one of the two mouse $\mathrm{X}$ chromosomes was shown by its lack of histone $\mathrm{H} 4$ acetylation to have undergone inactivation (Figure $3 \mathrm{G}$ ). Since $\mathrm{X}$ inactivation is not observed in non-transgenic polyploid male cells, these stud-
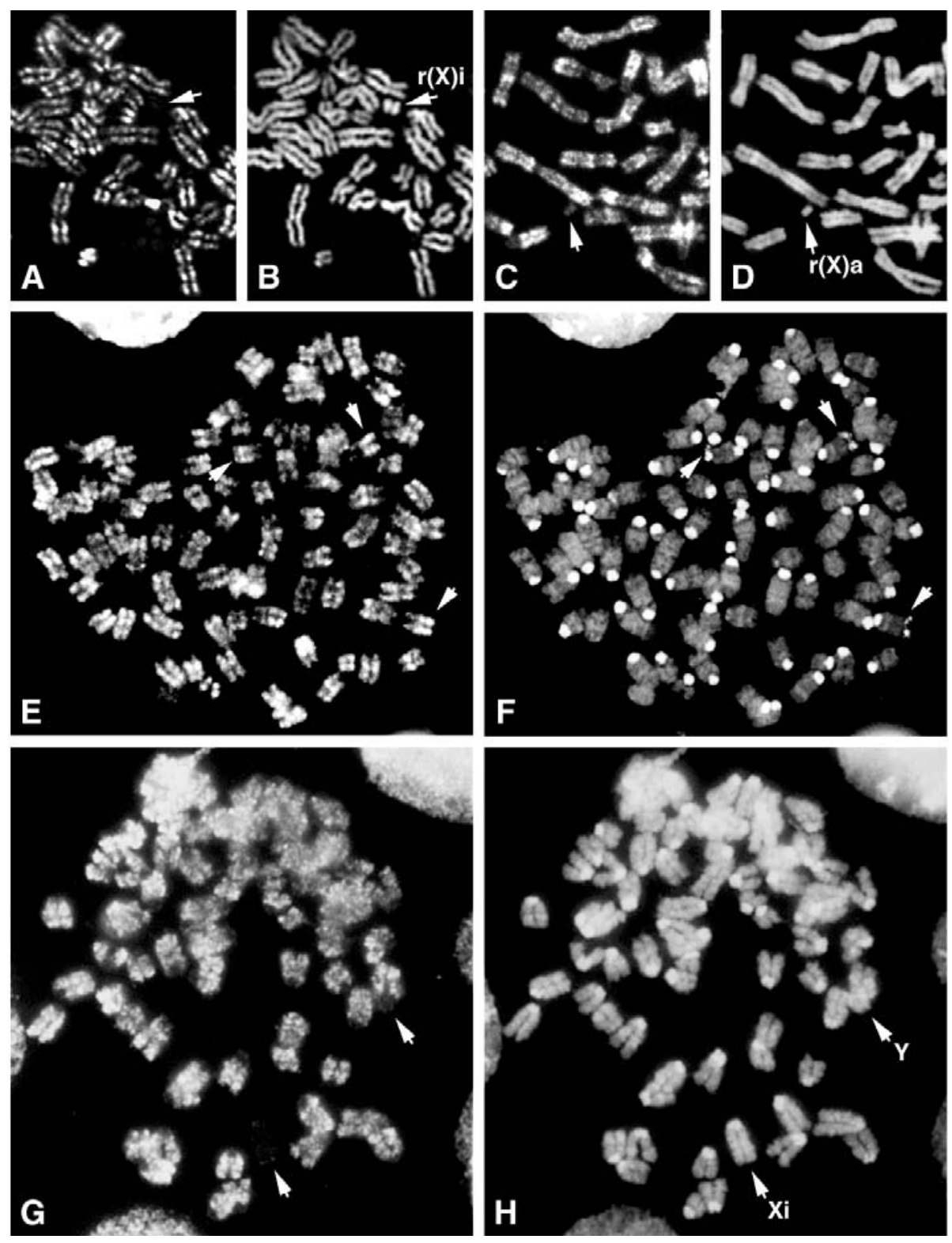

Figure 3 - Histone H4 underacetylation as an assay for X-inactivation. A,B - Partial metaphase of human lymphoblastoid cell from female subject possessing a large inactive ring X chromosome: A) indirect immunofluorescence with R5/12 anti-acetylated H4 antiserum (FITC); B) Hoechst 33258 fluorescent image of the same area of view, indicating the $\mathrm{r}(\mathrm{X}) \mathrm{i}$ chromosome. The arrow in $\mathbf{A}$ points to the position of the invisible ring lacking H4 acetylation. C,D - Partial metaphase of human skin fibroblast from female subject AL possessing a small ring $\mathrm{X}$ chromosome (Migeon et al., 1994): C) indirect immunofluorescence with R5/12 anti-acetylated H4 antiserum (FITC), with visibly immunolabelled ring (arrow); D) Hoechst 33258 fluorescent image of the same area of view: the acetylation of histone $\mathrm{H} 4$ shows the ring to be active (r(X)a). E,F - Metaphase from SV40 transformed mouse fibroblast line (male) with three chromosomes 11 that contain human XIST transgenes inserted near the telomeres of the long arms (Migeon et al., 1999): E) indirect immunofluorescence with R5/12 anti-acetylated $\mathrm{H} 4$ antiserum (TRITC), indicating the three chromosomes containing the transgenes (arrows); F) DAPI fluorescence image of the same cell with superimposed FISH signal (FITC) using a DNA probe for the transgene to identify sites of integration (arrows). No inactivation can be detected spreading from the transgenes (E), located at the distal ends of the chromosome 11 long arms (F). $\mathbf{G}, \mathbf{H}$ - Metaphase of different cell from the same SV40 transformed male mouse fibroblast line: G) indirect immunofluorescence with R5/ 12 anti-acetylated $\mathrm{H} 4$ antiserum (FITC); H) Hoechst 33258 fluorescence image of the same cell, indicating $\mathrm{X}$ and $\mathrm{Y}$ chromosomes. The $\mathrm{X}$ chromosome is underacetylated (arrow, G), showing that in this cell the presence of additional human XIST transgenes has induced an X chromosome in a male cell to undergo inactivation (Migeon et al., 1999). The largely heterochromatic Y chromosome is also underacetylated (arrow, $\mathbf{G}$ ). 
ies demonstrated that human XIST can function in mouse cells not only in local cis-inactivation, but also in the transcounting mechanism, whereby all but one XIC per diploid complement is inactivated.

\section{Methylated DNA-binding proteins}

Like histone acetylation, DNA methylation is a mechanism for making global modifications to chroma- tin structure that are almost certainly involved in epigenetic regulation. The majority of the $\mathrm{CpG}$ dinucleotide sequences present in mammalian DNA are methylated at the 5-cytosine position. An exception to this rule are CpGs contained in clusters at the 5'-ends of most housekeeping and many tissue specific genes, the so-called $\mathrm{CpG}$ islands. In contrast to the non-methylated state of $\mathrm{CpG}$ islands in general, those associated with several silenced genes that have been studied (i.e., on the inactive X chro-
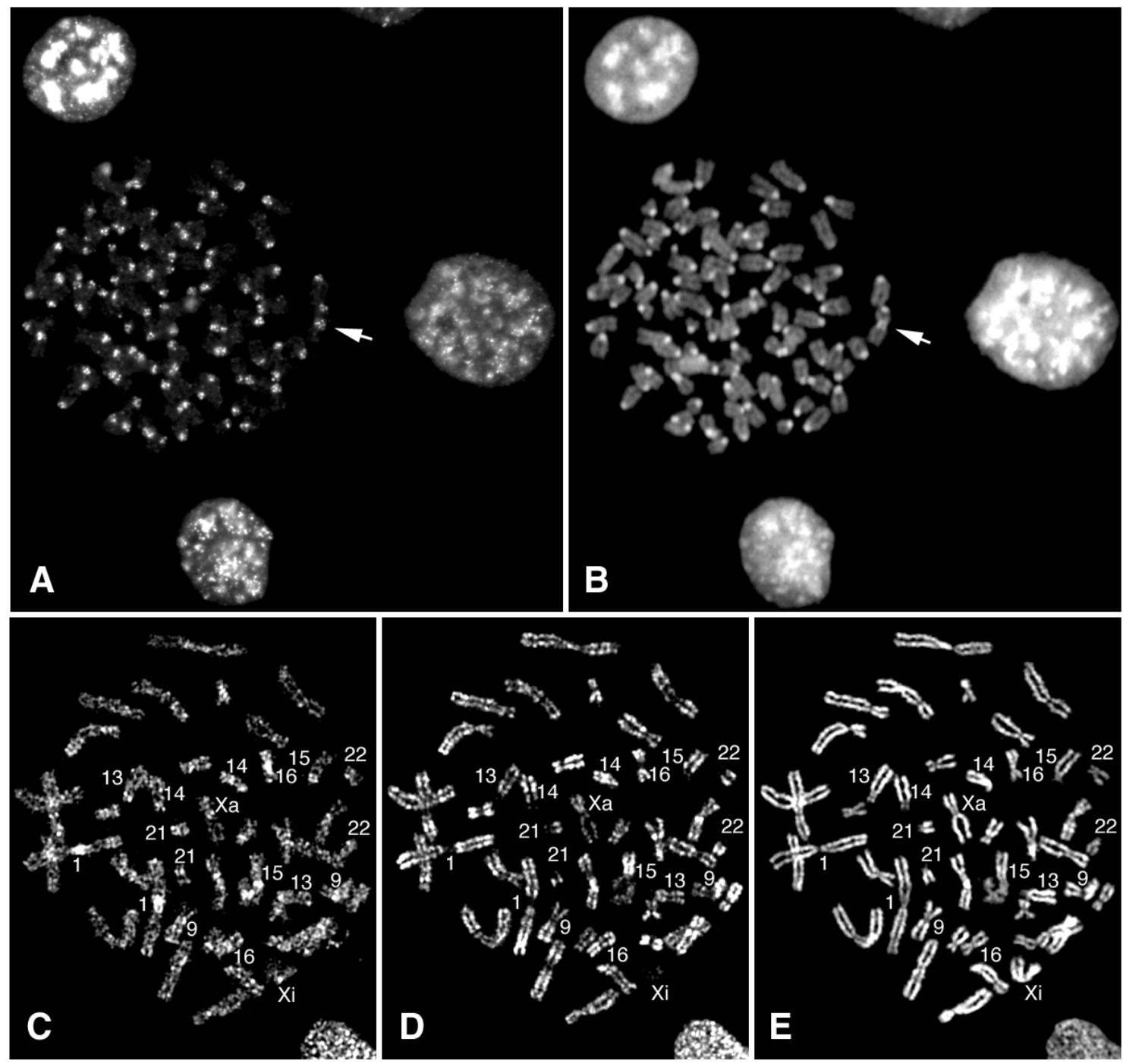

Figure 4 - Localization of methylated DNA-binding proteins. A,B - Distribution of MeCP2 in the mouse mammary tumour cell line C127: A) metaphase and interphase cells observed by indirect immunofluorescence (FITC) using anti-MeCP2 rabbit antiserum as the primary antibody; B) Hoechst 33258 fluorescence image of the same field of view. In both metaphase and interphase, MeCP2 is seen to be concentrated in DNA domains corresponding to mouse centric heterochromatin, identified in $\mathbf{B}$ by its bright fluorescence with Hoechst 33258. A marker metaphase chromosome deriving from a head-to-tail fusion of two acrocentric chromosomes (arrows) clearly shows the association of MeCP2 with the interstitial block of heterochromatin (A). There appears to be very little MeCP2 on euchromatin in metaphase. C,E - Distribution of MBD1 on metaphase chromosomes of primary human female fibroblast line HF19 (Ng et al., 2000): C) indirect immunofluorescent labelling of metaphase cell using anti-(human) MBD1 sheep antiserum (TRITC); D) the same cell showing distribution of acetylated histone H4, observed by simultaneous immunolabelling with R5/12 anti-acetylated histone H4 rabbit antiserum (FITC); E) Hoechst 33258 fluorescence image of the same cell. It can be seen in $\mathbf{C}$ that the major locations of constitutive heterochromatin in the human karyotype (identified by chromosome in each panel) are also enriched for MBD1, as well as there being a non-uniform but specific MBD1 labelling pattern along the euchromatic chromosome arms. The histone $\mathrm{H} 4$ acetylation banding in $\mathbf{D}$ serves to identify the inactive $\mathrm{X}$ chromosome (Xi) and also helps to recognize the autosomes by their R-like banding. There is no significant difference in MBD1 decoration of the active and inactive X chromosomes, and the MBD1 euchromatin distribution, in general, is different from both R-like bands (D) and G-like bands (E). 
mosome) become methylated subsequent to silencing, implicating DNA methylation in long-term gene inactivation. A number of proteins have been identified that bind to 5-methylcytosine, one of the first to be characterized being MeCP2 (Lewis et al., 1992). Transcription studies have indicated that $\mathrm{MeCP} 2$ acts as a transcriptional repressor of genes associated with methylated $\mathrm{CpG}$ islands. Recently, it has been shown that mutations within the human MeCP2 gene can give rise to a clinical disorder in human development, Rett syndrome.

A motif within MeCP2 containing the methylated DNA-binding domain (MBD) has now been identified in other gene sequences, defining a family of MBD proteins. Most MBD proteins have turned out to be repressors of transcription at methylated $\mathrm{CpG}$ islands in vitro, where they appear to act as components of complexes containing histone deacetylase. Because of their involvement in gene silencing, it is of interest to study the distribution of methylated DNA-binding proteins on metaphase chromosomes to see if any correlation with cytogenetically defined domains can be detected. On mouse metaphase chromosomes $\mathrm{MeCP} 2$ was found to be concentrated in centric heterochromatin (Figure 4A), where the major satellite DNA sequences are located that contain over $40 \%$ of total mouse 5-methylcytosine (Lewis et al., 1992). Recently, the MBD family member MBD1 has been localized on human metaphase chromosomes (Figure 4C,E), where it is enriched in pericentromeric heterochromatin, but is also associated with euchromatin giving a specific pattern of immunofluorescence along the chromosome arms ( $\mathrm{Ng}$ et al., 2000). This pattern appears to be different from those produced by standard cytogenetic banding techniques, and is currently being studied in more detail.

\section{ACKNOWLEDGMENTS}

I am grateful to the Medical Research Council for supporting this programme of research. I should like to thank Professor Máximo Drets, Dr. Gustavo Folle and Dr. Wilner MartínezLópez for inviting me to participate in the International PostGraduate Course: 'New Approaches in the Study of RadiationInduced and Cancer-Associated Chromosomal Aberrations', held in Montevideo, May 22-31, 2000, at which these observations were presented.

\section{RESUMO}

O controle da informação genética codificada pelo DNA em cromossomos de mamíferos é mediado por proteínas, algumas das quais estão apenas temporariamente ligadas enquanto que outras estão intrinsecamente associadas com ácido nucléico na mistura complexa conhecida por cromatina. Proteínas associadas com cromatina variam desde as ubíquas e abundantes histonas até os mais específicos e raros entre os fatores de transcrição. Embora muitas proteínas de cromatina sejam provavelmente excluídas dos cromossomos mitóticos altamente condensados, muitas delas são retidas durante todo o ciclo celular e podem ser detectadas nos cromossomos em esfregaços de metáfase. Comparando a distribuição de uma proteína cromossômica com marcadores citogenéticos conhecidos em cromossomos em metáfase, pode-se obter uma primeira fonte de dados importante e potencialmente muito informativa a respeito da função da proteína em estudo. O objetivo do presente estudo é resumir alguns dos princípios envolvidos na obtenção de preparações cromossômicas adequadas para subseqüente imunolocalização dos antígenos protéicos. Algumas aplicações do método serão incluídas para ilustrar como esta abordagem aumentou nossa compreensão da estrutura cromossômica e da regulação genética.

\section{REFERENCES}

Gooderham, K. and Jeppesen, P. (1983). Chinese hamster metaphase chromosomes isolated under physiological conditions: a partial characterization of associated non-histone proteins and protein cores. Exp. Cell Res. 144: 1-14.

Holmquist, G.P. (1992). Chromosome bands, their chromatin flavors, and their functional features. Am. J. Hum. Genet. 51: 17-37.

Jeppesen, P. (1993). Indirect immunofluorescence of unfixed mammalian metaphase chromosomes: method and applications. Rev. Bras. Genet. 16: 485-508.

Jeppesen, P. (1997). Histone acetylation: a possible mechanism for the inheritance of cell memory at mitosis. Bioessays 19: 67-74.

Jeppesen, P. and Turner, B.M. (1993). The inactive X chromosome in female mammals is distinguished by a lack of histone $\mathrm{H} 4$ acetylation, a cytogenetic marker for gene expression. Cell 74: 281-289.

Jeppesen, P., Mitchell, A., Turner, B. and Perry, P. (1992). Antibodies to defined histone epitopes reveal variations in chromatin conformation and underacetylation of centric heterochromatin in human metaphase chromosomes. Chromosoma 101:322-332.

Lewis, J.D., Meehan, R.R., Henzel, W.J., Maurer-Fogy, I., Jeppesen, P. and Bird, A. (1992). Purification, sequence, and cellular localization of a novel chromosomal protein that binds to methylated DNA. Cell 69: 905-914.

Migeon, B.R., Luo, S., Jani, M. and Jeppesen, P. (1994). The severe phenotype of females with tiny ring $\mathrm{X}$ chromosomes is associated with inability of these chromosomes to undergo $\mathrm{X}$ inactivation. Am. $J$. Hum. Genet. 55: 497-504.

Migeon, B.R., Kazi, E., Haisley-Royster, C., Hu, J., Reeves, R., Call, L., Lawler, A., Moore, C.S., Morrison, H. and Jeppesen, P. (1999). Human $\mathrm{X}$ inactivation center induces random $\mathrm{X}$ chromosome inactivation in male transgenic mice. Genomics 59: 113-121.

Ng, H.-H., Jeppesen, P. and Bird, A. (2000). Active repression of methylated genes by the chromosomal protein MBD1. Mol. Cell. Biol. 20: 1394-1406.

Stenman, S., Rosenqvist, M. and Ringertz, N.R. (1975). Preparation and spread of unfixed metaphase chromosomes for immunofluorescence staining of nuclear antigens. Exp. Cell Res. 90: 87-94.

Surrallés, J., Jeppesen, P., Morrison, H. and Natarajan, A.T. (1996). Analysis of loss of inactive $\mathrm{X}$ chromosomes in interphase cells. Am. J. Hum. Genet. 59: 1091-1096.

Turner, B.M. and Fellows, G. (1989). Specific antibodies reveal ordered and cell-cycle-related use of histone-H4 acetylation sites in mammalian cells. Eur. J. Biochem. 179: 131-139.

(Received November 23, 2000) 